\title{
Acute Fibrinous and Organizing Pneumonia Case Report and Review: Distinguishing AFOP from Similar Organizing Pneumonias
}

\author{
Chaudhary NM ${ }^{1 *}$, Crowell W2 ${ }^{2}$, Katzman J H³ \\ Klinkova $\mathrm{O}^{4}$ and Greene $\mathrm{J}^{5}$ \\ ${ }^{1}$ G.M.E.R.S. Medical College Dharpur Patan, College of \\ Medicine, Gujarat, India \\ ${ }^{2}$ University of South Florida, Division of Infectious \\ disease \& International Medicine, USA \\ ${ }^{3}$ College of Medicine, University of South Florida, USA \\ ${ }^{4}$ Hospital Medicine and Infectious Disease, H. Lee Moffitt \\ Cancer Center, USA \\ ${ }^{5}$ Infectious Disease \& Epidemiology, H. Lee Moffitt \\ Cancer Center, USA \\ *Correspondling author: Nirali M Chaudhary, \\ G.M.E.R.S. Medical College Dharpur Patan, College of \\ Medicine, Gujarat, India
}

Received: September 06, 2021; Accepted: September 24, 2021; Published: October 01, 2021

\section{Introduction}

Acute Fibrinous and Organizing Pneumonia (AFOP) was first described by Beasely et al. in 2002 as a unique histological pattern of intra-alveolar balls of fibrin [1]. However, its vague symptoms make it impossible to make a diagnosis without an open lung biopsy [2]. Indeed, many tests and medications are used for diagnosis and treatment before AFOP is diagnosed [3]. Diagnosis is further complicated in cancer patients who are more susceptible to respiratory tract infections [4], which may mimic AFOP. Delays in diagnosis are concerning since the worse cases of AFOP can have a mortality rate as high as $90 \%$ in the presence of poor-prognostic indicators, such as mechanical ventilation [5]. This case study compares two patients with cancer, one of whom with AFOP and the other with Cryptogenic Organizing Pneumonia (COP). It will also provide background information of other organizing pneumonias, such as Bronchiolitis Obliterans Syndrome (BOS), Diffuse Alveolar Damage (DAD), and Eosinophilic Pneumonia (EP). These conditions should be included in the differential diagnosis of persistent or slowly resolving pneumonias, especially in immunocompromised patients.

\section{Case Presentation}

\section{Case 1}

A 47 year old male with relapsed pre-B Acute Lymphoblastic Leukemia (ALL), status post haploidentical allogenic stem cell transplant two years ago, receiving chemotherapy with Blinatumomab, acyclovir and Bactrim prophylaxis, presented with fever, cough with sputum production, and shortness of breath on exertion. He was recently admitted to the hospital with diagnosis of sepsis secondary to bilateral Pseudomonas Aeruginosa pneumonia as well as Rhinovirus, and Parainfluenza infections. He was discharged home 15 days prior to current presentation. His laboratory work-up during current admission revealed leukocytosis and lymphopenia; respiratory viral panel was persistently positive for rhinovirus. CT Angiogram on admission showed persistent pneumonia with areas of worsening consolidation, and ground-glass attenuation (Figure 1 and 2).

Post-viral BOS was suspected. On hospital day 8, wedge resections were performed on the patient's right upper, middle, and lower lobes. The histology demonstrated acute and organizing pneumonia with intra-alveolar hemorrhage and fibrin deposition. Additionally, there was acute bronchiolitis with dense peribronchiolar infiltrate of acute inflammatory cells, and a neutrophilic intraluminal exudate. The samples were negative for hyaline membranes, or intraluminal fibroblastic plugs involving terminal airways. He was diagnosed with AFOP and discharged with prednisone $40 \mathrm{mg}$ daily which caused initial improvement, followed by a prolonged steroid taper. Thirty days after his second admission, he returned back with worsening hypoxia and hypotension. Laboratory results revealed leukocytosis, and hypoalbuminemia. He was admitted to intensive care unit and

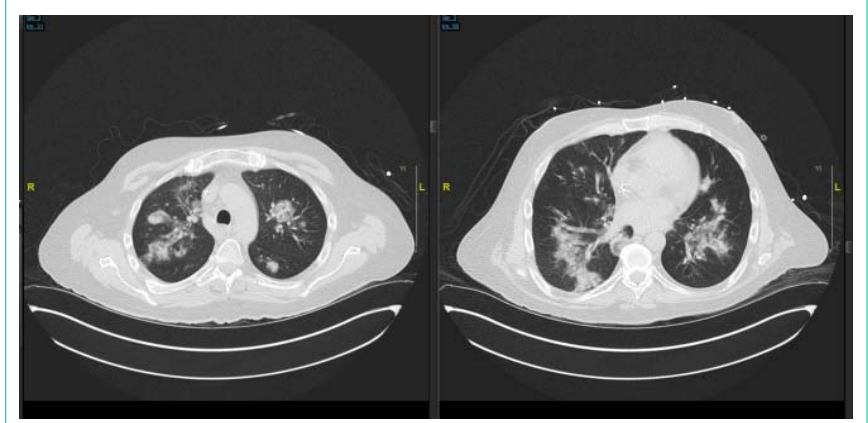

Figure 1: From CT scan of patient 1 showing consolidation and ground glass appearance from previous hospital course.
J Fam Med - Volume 8 Issue 7 - 2021

ISSN : 2380-0658 | www.austinpublishing group.com

Chaudhary et al. $($ All rights are reserved
Citation: Chaudhary NM, Crowell W, Katzman JH, Klinkova O and Greene J. Acute Fibrinous and Organizing Pneumonia Case Report and Review: Distinguishing AFOP from Similar Organizing Pneumonias. J Fam Med. 2021; 8(7): 1271 


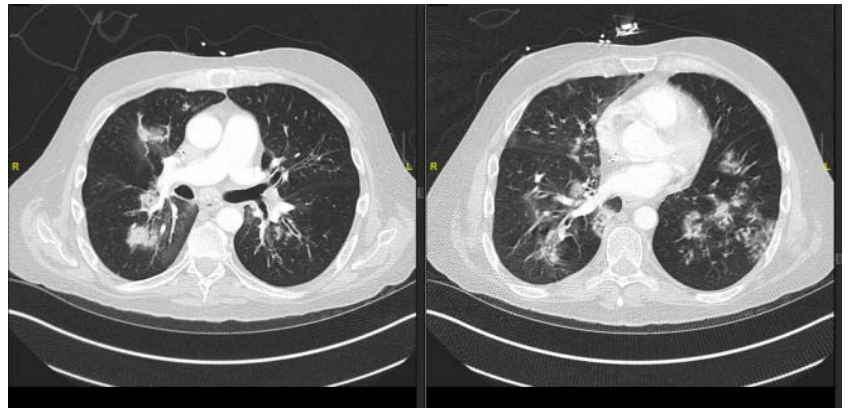

Figure 2: CT scan of patient 1 at time of presentation showing increased consolidation and ground glass appearance.

received broad-spectrum antibiotics, mechanical ventilation, and IV fluid hydration. Over the course of the evening he suffered 3 cardiac arrests, and a large right-sided pneumothorax. He ultimately expired 31 days after presentation.

\section{OP case}

A 67 year old Caucasian male with a history of multiple myeloma, status post autologous stem cell transplant three years ago, presented in early 2018 with a cough, fever, chills, sore throat, and sputum production. He indicated that lying on the right side worsened his cough and that the cough would bring up sputum. He denied history of aspiration, smoking, or significant alcohol use. However, he reported having two respiratory infections in the last year. Multiple myeloma was treated with intermittent Revlimid in an outpatient setting, which caused a rash. Patient underwent skin biopsy that revealed interstitial granulomatous dermatitis that was treated with three courses of corticosteroids, the longest being 6 weeks. This particular entity made him at a higher risk for granuloma formation in other organs. The rash has since resolved. An x-ray performed at initial presentation showed no infiltrates, however, due to suspicion for respiratory infection, he was placed on doxycycline. His symptoms improved but then recurred four months later, and a PET scan was ordered. The PET scan (Figure 3) showed a new 3-4 $\mathrm{cm}$ nodular consolidation in the lower right posterior lobe. There was hypermetabolic rounded consolidation in the posterior right lower lobe (Figure 4) that indicated inflammation, infection, atelectasis, or neoplasia. There were mildly hypermetabolic right axillary lymph nodes, which were likely reactive.

Open lung biopsy showed granulomatous inflammation and organizing pneumonitis. Numerous intra-alveolar macrophages were

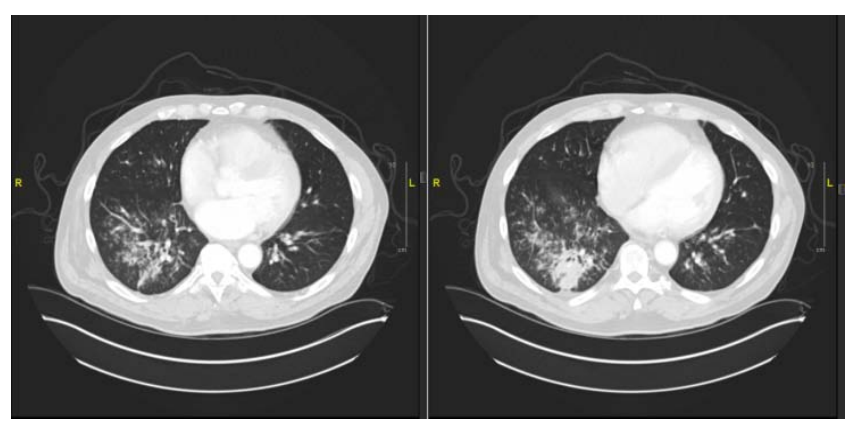

Figure 3: PET scan of Patient 2 with nodular consolidations.

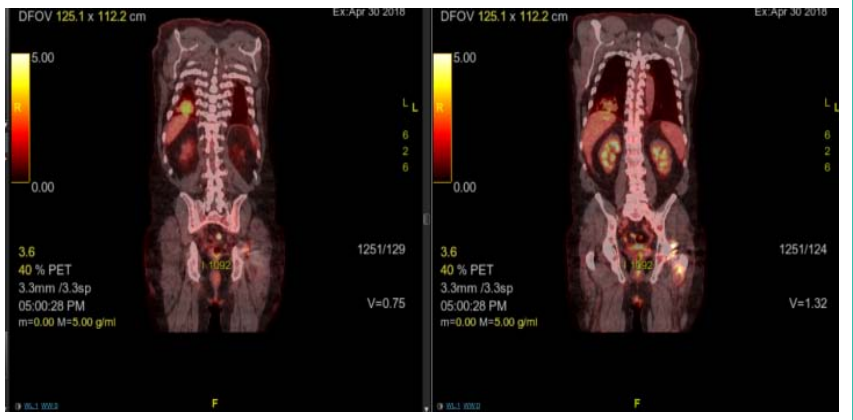

Figure 4: PET scan of Patient 2 showing hypermetabolic rounded consolidation of the lower right lobe.

detected in multiple foci. There was additional lymphoplasmocytic infiltrate in the peribronchiolar and peribronchial tissue.

Six months after the initial presentation the patient continued to experience fevers, productive coughing, chills, and non-drenching sweats. CT scan of the chest demonstrated improvement of the consolidation with new tree-in-bud nodules.

\section{Discussion}

\section{AFOP}

Histological signs: Acute Fibrinous Organizing Pneumonia (AFOP) is a histological pattern characterized by a patchy distribution of intra-alveolar fibrin balls that lack hyaline membranes [1]. Interstitial changes include acute or chronic inflammation, presence of neutrophils, hyperplasia of type 2 pneumocytes, and alveolar septal expansion with myxoid connective tissue [1]. The interstitial changes are mild to moderate in severity and concentrated around intra-alveolar fibrin [1]. The interstitial tissues further from the intraalveolar fibrin lack these characteristics [1]. Features that are not observed include hyaline membranes, extensive bronchopneumonia, abscess formation, granulomatous inflammation. Eosinophils are inconspicuous or absent [1].

Associated conditions: AFOP has been associated with autoimmune diseases, infections, certain medications, prolonged corticosteroid use, HIV, lung transplant, occupational exposure, and hematological disorders [6] like acute leukemia and multiple myeloma [3]. However, it is sometimes not possible to find an instigating factor [6].

In the case being presented, the AFOP patient was persistently shedding rhinovirus. While this hasn't been indicated as a cause of AFOP previously [3,7], rhinovirus has demonstrated the ability to induce an inflammatory response [8]. Epithelium infected with the virus expresses IL-6 and IL-8, which induce inflammation and neutrophilic attraction8. Rhinovirus also upregulated ICAM-1, which is the virus's receptor as well as an important part of the inflammatory process [9]. Furthermore, rhinovirus upregulates basic Fibroblastic Growth Factor (bFGF) in vitro, which is associated with fibroblast proliferation [10]. These in vitro tests are supported by bFGF release after a rhinovirus-induced asthma exacerbation [10]. Therefore, rhinovirus's ability to stimulate the immune system and remodel the airway may contribute to the pathogenesis of AFOP in patients who are persistently shedding the virus. 


\begin{tabular}{|c|c|c|c|c|c|}
\hline Disorder & Symptoms & Associated Conditions & CT Scans & Histology & Treatment \\
\hline AFOP & $\begin{array}{l}\text { Fever, cough, chest } \\
\text { pain, dyspnea, fatigue, } \\
\text { and hemoptysis [5-7] }\end{array}$ & $\begin{array}{l}\text { Autoimmune diseases, infections, certain } \\
\text { medications, prolonged corticosteroid } \\
\text { use, HIV, lung transplant, occupational } \\
\text { exposure, and hematological disorders }\end{array}$ & $\begin{array}{l}\text { Diffuse } \\
\text { consolidation, } \\
\text { ground glass } \\
\text { opacities, nodules } \\
\text { and masses. }\end{array}$ & $\begin{array}{l}\text { Intra-alveolar fibrin balls, interstitial } \\
\text { acute or chronic interstitial } \\
\text { inflammation, hyperplasia of type } 2 \\
\text { pneumocytes, and alveolar septal } \\
\text { expansion with myxoid connective } \\
\text { tissue [1] }\end{array}$ & Corticoteroids [7] \\
\hline $\mathrm{COP}$ & $\begin{array}{l}\text { Fever, coughing, } \\
\text { dyspnea, wheezing, } \\
\text { fatigue, hemoptysis, } \\
\text { respiratory failure, and } \\
\text { chest pain [12] }\end{array}$ & & $\begin{array}{l}\text { Diffuse } \\
\text { consolidation, } \\
\text { ground glass } \\
\text { opacities, nodules } \\
\text { and masses. }\end{array}$ & $\begin{array}{l}\text { Masson bodies }{ }^{15}, \text { pale-staining } \\
\text { matrix [11], inflammatory cells [13], } \\
\text { alveolar septae are not damaged, } \\
\text { but may be slightly thickened with } \\
\text { cellular infiltrate [13] }\end{array}$ & Corticoteroids [12] \\
\hline BOS & $\begin{array}{l}\text { Cough, dyspnea, } \\
\text { sputum production } \\
\text { fever, hypoxia, and } \\
\text { adventitious lung } \\
\text { sounds }\end{array}$ & $\begin{array}{l}\text { Lung transplant w/ chronic allograft } \\
\text { rejection, hematopoietic stem cell } \\
\text { transplant with GVHD, connective } \\
\text { tissue diseases, lower respiratory tract } \\
\text { infections, inhalation of toxic fumes, and } \\
\text { occupational exposures, idiopathic [20] }\end{array}$ & & $\begin{array}{l}\text { Submucosal bronchiolar fibrosis, } \\
\text { narrowing of the lumen, and } \\
\text { fibrogenic deposition in the small } \\
\text { airways and bronchioles [18] }\end{array}$ & $\begin{array}{l}\text { Immuno-suppression } \\
\text { or immune-modulation } \\
{[17,19]}\end{array}$ \\
\hline EP & $\begin{array}{l}\text { Cough, wheezing, } \\
\text { dyspnea, and } \\
\text { hemoptysis [22] }\end{array}$ & $\begin{array}{l}\text { Parasitic infections, allergic sensitization } \\
\text { medication reaction, toxins, or idiopathic } \\
\text { [22] }\end{array}$ & & $\begin{array}{l}\text { Prominent intra-alveolar fibrin and } \\
\text { extensive eosinophil parenchymal } \\
\text { infiltrates [14] }\end{array}$ & $\begin{array}{l}\text { Treating underlying } \\
\text { infection, and } \\
\text { corticosteroids [22] }\end{array}$ \\
\hline
\end{tabular}

Clinical symptoms: Clinical symptoms of AFOP include fever, cough, chest pain, dyspnea, fatigue, and hemoptysis [5-7]. Patients can present with AFOP in two ways. One form is acute and rapidly progressing with poorer prognosis, while the other subacute form has a more prolonged onset of symptoms $[7,11]$.

Treatment of AFOP: A standard treatment is difficult to definitively determine due to the rarity of the disease and its various clinical presentations [6]. However, corticosteroids are the most successful treatment described [7]. This is common among organizing pneumonias since their treatment usually includes immunomodulation with corticosteroids.

\section{AFOP vs. COP}

It can be particularly difficult to distinguish AFOP from cryptogenic organizing pneumonia (COP, also known as bronchiolitis obliterans with organizing pneumonia or BOOP). In fact, Feinstein et al. reported that only fever was statistically significantly more common in AFOP than COP [12]. The symptoms measured that were not significantly different included coughing, dyspnea, wheezing, fatigue, hemoptysis, respiratory failure, and chest pain [12]. To further complicate the issue, there was only one significant difference in the radiographic findings (89\% of COP patients had nodules or masses while $70 \%$ of AFOP had the same) [12]. The other radiological abnormalities that were not statistically different were location in lung, rate of consolidation, ground-glass appearance, air bronchograms, adenopathy, honeycombing, pleural effusion, cavitation, reverse halo sign, bronchiectasis, and fibrosis [12]. The very similar symptoms and imaging profiles of our patients emphasizes the difficulty physicians may have differentiating the two diseases. Therefore, both COP and AFOP will required a large lung sample for histology, since a transbronchial biopsy may not provide sufficient tissue for a definitive diagnosis $[13,14]$.

A key histological pattern that distinguishes COP from AFOP is the fibrous plugs called Masson bodies. Masson bodies consist of fibroblasts and myofibroblasts in the alveoli, alveolar ducts, and terminal bronchioles [15], surrounded by pale-staining matrix [11]. Masson bodies may be accompanied by inflammatory cells, such as lymphocytes, plasma cells and macrophages [13]. Granulation tissue often involves, and obstructs, adjacent bronchioles [16]. However, the alveolar septae are not damaged, but may be slightly thickened with cellular infiltrate13. Masson bodies are a clear distinction from AFOP, where they do not occur [14].

There are several non-infection pneumonias, seen in Table 1, which further complicate the differential diagnosis.

\section{Other Organizing Pneumonias \\ Bos}

Bronchiolitis obliterans syndrome (BOS, also known as obliterative bronchiolitis or constrictive bronchiolitis [17]) lesions demonstrate submucosal bronchiolar fibrosis, narrowing of the lumen, and fibrogenic deposition in the small airways and bronchioles [18]. Symptoms of BOS include cough, dyspnea, sputum production fever, hypoxia, and adventitious sounds on lung auscultation [19]. BOS is most often associated with lung transplant with chronic allograft rejection, or hematopoietic stem cell transplant patients with graft versus host disease. However, it is also associated with connective tissue diseases, lower respiratory tract infections, inhalation of toxic fumes, and occupational exposures, but it can be idiopathic [20]. The treatment focuses around immunosuppression and immunomodulation $[17,19]$.

\section{DAD}

Key histological patterns of Diffuse Alveolar Damage (DAD) include hyaline membranes [11,14], edema of the alveolar walls [11], and occasionally includes focal intra-alveolar fibrin deposition similar to AFOP [14]. Reported symptoms include exertional dyspnea, cough, fever, chest pain, and hemoptysis [21]. Diffuse Alveolar Damage (DAD) is a reaction to wide range of factors including infection, drugs, toxic inhalation, or it can be idiopathic [11]. Treatment for DAD includes antibacterial therapy, corticosteroids, Intravenous 
cyclophosphamide, and antivirals [21].

\section{EP}

The histology of Eosinophilic Pneumonia (EP) is characterized by prominent intra-alveolar fibrin and extensive eosinophil parenchymal infiltrates [14]. EP has both infectious (largely parasitic in nature) and non-infectious causes (allergic sensitization and exposure to certain medications or toxins), but it can also be idiopathic [22]. It can be treated with corticosteroids, but if it is not idiopathic, the underlying cause must be treated as well [22].

\section{Importance of Histological Sample}

Diagnosis of AFOP is difficult not only due to similar presentations to other conditions [11], but because CT scans for the acute and subacute forms of AFOP are different. Bilateral basilar infiltrates and ground-glass opacities are associated with the acute form, which is similar to diffuse alveolar damage (DAD) $[11,23]$. CT scans of the subacute form can demonstrate both a focal or diffuse pattern of parenchymal abnormalities, which is indistinguishable from Organizing Pneumonia (OP). The focal form shows consolidation with lobular sparing or peripheral sparing with multiple septal lines [11], while the diffuse form shows multiple miliary nodules [11,23]. These nodules further complicate diagnosis since they resemble cancer [12]. This is especially important in cancer patient populations, such as ours, where recurrence is always a concern. Again, the only way to overcome these issues is with histology samples [5,7].

\section{Conclusion}

AFOP is a serious disease with lethal potential and should therefore be considered in the differential diagnosis, especially in cases where the patient is continually shedding rhinovirus, which's inflammatory and airway-remodeling capabilities may contribute to the disease. While obtaining a biopsy for a larger sample size may seem like an undue burden on the patient, applied judiciously, it may give the physician the information they need to start definitive treatment. It should be noted that the treatment for all of the examples of organizing pneumonia discussed in this paper include corticosteroids, and therefore exposing the patient to the risk associated with a large-sample biopsy should be weighed against the benefit of confirming the diagnosis.

\section{References}

1. Beasley MB, Franks TJ, Galvin JR, Gochuico B, Travis WD. Acute fibrinous and organizing pneumonia: a histological pattern of lung injury and possible variant of diffuse alveolar damage. Archives of pathology \& laboratory medicine. 2002; 126: 1064-1070.

2. Valim V, Rocha RH, Couto RB, Paixão TS, Serrano ÉV. Acute Fibrinous and Organizing Pneumonia and Undifferentiated Connective Tissue Disease: A Case Report. Case Reports in Rheumatology. 2012; 2012: 1-6.

3. Dai J-H, Li H, Shen W, Miao L-Y, Xiao Y-L, Huang M, et al. Clinical and Radiological Profile of Acute Fibrinous and Organizing Pneumonia: A Retrospective Study. Chinese medical journal. 2015; 128: 2701-2706.

4. Rolston KVI. Infections in Cancer Patients with Solid Tumors: A Review. Infectious diseases and therapy. 2017; 6: 69-83.

5. Arnaud D, Surani Z, Vakil A, Varon J, Surani S. Acute Fibrinous and Organizing Pneumonia: A Case Report and Review of the Literature. The American journal of case reports. 2017; 18: 1242-1246.

6. Gomes R, Padrão E, Dabó H, Soares Pires F, Mota P, Melo N, et al. Acute fibrinous and organizing pneumonia: A report of 13 cases in a tertiary university hospital. Medicine. 2016; 95: e4073.

7. Kuza C, Matheos T, Kathman D, Heard SO. Life after acute fibrinous and organizing pneumonia: a case report of a patient 30 months after diagnosis and review of the literature. Journal of Critical Care. 2016; 31: 255-261.

8. Papadopoulos NG, Papi A, Psarras S, Johnston SL. Mechanisms of rhinovirus-induced asthma. Paediatric Respiratory Reviews. 2004; 5: 255260.

9. Zimmerman T, Blanco FJ. Inhibitors targeting the LFA-1/ICAM-1 cell-adhesion interaction: design and mechanism of action. Current pharmaceutical design. 2008; 14: 2128-2139.

10. Skevaki CL, Psarras S, Volonaki E, Pratsinis H, Spyridaki IS, Gaga M, et al. Rhinovirus-induced basic fibroblast growth factor release mediates airway remodeling features. Clinical and Translational Allergy. 2012; 2: 14.

11. Kligerman SJ, Franks TJ, Galvin JR. From the Radiologic Pathology Archives: Organization and Fibrosis as a Response to Lung Injury in Diffuse Alveolar Damage, Organizing Pneumonia, and Acute Fibrinous and Organizing Pneumonia. Radio Graphics. 2013; 33: 1951-1975.

12. Feinstein MB, DeSouza SA, Moreira AL, Stover DE, Heelan RT, Iyriboz TA, et al. A comparison of the pathological, clinical and radiographical, features of cryptogenic organising pneumonia, acute fibrinous and organising pneumonia and granulomatous organising pneumonia. Journal of clinical pathology. 2015; 68: 441-447.

13. Torrealba JR, Fisher S, Kanne JP, Butt YM, Glazer C, Kershaw C, et al. Pathology-radiology correlation of common and uncommon computed tomographic patterns of organizing pneumonia. Human Pathology. 2018; 71 : $30-40$.

14. Nguyen L-P, Ahdoot S, Sriratanaviriyakul N, Zhang Y, Stollenwerk N, Schivo $\mathrm{M}$, et al. Acute Fibrinous and Organizing Pneumonia Associated With Allogenic Hematopoietic Stem Cell Transplant Successfully Treated With Corticosteroids: A Two-Patient Case Series. Journal of investigative medicine high impact case reports. 2016; 4: 2324709616643990.

15. Huo J-P, Liu C, Jin B-B, Duan F-X, Mei S-H, Li X-G, et al. Cryptogenic organizing pneumonia masquerading as lung carcinoma: $\mathrm{A}$ case report and review of the literature. Experimental and therapeutic medicine. 2018; 15: 39-46.

16. Cottin V, Cordier J-F. Cryptogenic Organizing Pneumonia. Seminars in Respiratory and Critical Care Medicine. 2012; 33: 462-475.

17. Barker AF, Bergeron A, Rom WN, Hertz MI. Obliterative Bronchiolitis. New England Journal of Medicine. 2014; 370: 1820-1828.

18. Yoshihara S, Yanik G, Cooke KR, Mineishi S. Bronchiolitis obliterans syndrome (BOS), bronchiolitis obliterans organizing pneumonia (BOOP), and other late-onset noninfectious pulmonary complications following allogeneic hematopoietic stem cell transplantation. Biology of blood and marrow transplantation: journal of the American Society for Blood and Marrow Transplantation. 2007; 13: 749-759.

19. Hayes D, Jr. A review of bronchiolitis obliterans syndrome and therapeutic strategies. Journal of cardiothoracic surgery. 2011; 6: 92.

20. Lynch J, Weigt S, DerHovanessian A, Fishbein M, Gutierrez A, Belperio J. Obliterative (Constrictive) Bronchiolitis. Seminars in Respiratory and Critical Care Medicine. 2012; 33: 509-532.

21. Parambil JG, Myers JL, Aubry M-C, Ryu JH. Causes and Prognosis of Diffuse Alveolar Damage Diagnosed on Surgical Lung Biopsy. Chest. 2007; 132: 50 57.

22. Akuthota P, Weller PF. Eosinophilic pneumonias. Clinical microbiology reviews. 2012; 25: 649-660.

23. Garcia BA, Goede T, Mohammed T-L. Acute Fibrinous Organizing Pneumonia: A Case Report and Literature Review. Current Problems in Diagnostic Radiology. 2015; 44: 469-471. 